\title{
Impacts of open innovation on company business models: A case study of demand-driven co-creation
}

\author{
Heini Malm \\ heini.malm@businessoulu.com | BusinessOulu, Economic Development Organisation, City of Oulu \\ Minna Pikkarainen \\ minna.pikkarainen@oulu.fi | University of Oulu, Oulu Business School, Faculty of Medicine, VTT, \\ Technical Research Centre of Finland \\ Elina Hyrkäs \\ elina.hyrkas@oulu.fi| University of Oulu, Oulu Business School, Finland
}

\begin{abstract}
Research on open innovation refers to a model in which innovation is driven by the needs of the customer. In the healthcare sector, healthcare organisations are often the core customers for companies that want to use e-health solutions to improve patient care and cost efficiency. We examined the impact of coupled open innovation on companies' business models. Co-creation between network actors was carried out in a demand-driven manner based on the needs of healthcare professionals. We present the initial findings of a longitudinal case -study in an international setting. The research generated a new, collaborative, open business modelling framework for fact-based value creation that supports companies in the challenging task of exploring economically viable business opportunities. Our paper contributes to the knowledge management and open business model literatures by providing empirical knowledge on the impact of coupled open innovation in the company business models in the knowledgebased economy.
\end{abstract}

Keywords. Business models; Open innovation; Coupled Open Innovation; Demand-driven Open Innovation; Knowledge Management; Healthcare Management.

Cite paper as: Malm, H., Pikkarainen, M., Hyrkäs, E., (2020). Impacts of open innovation on company business models: A case study of demand-driven co-creation, Journal of Innovation Management, www.open-jim.org, 8(3), $75-108$. 


\section{Introduction}

Imagine that you are the CEO in an e-health company. Your strategy is to implement either patient- or hospital-driven innovations in a complex healthcare market. You know, that in reality, 'in healthcare, most technological enablers have failed to bring about lower costs, higher quality, and greater accessibility' (as described by Hwang \& Christensen, 2018). So far, you have only tried out the traditional technology-push innovation development model, which often leads to a situation where the developed solutions might not meet the actual needs of healthcare providers and thus, might not lead to business success. Now, through an EU-wide public call and a company selection process, you have received an invitation to take part in a demand-driven open innovation project, with a healthcare organisation as a potential customer.

What impact does open innovation have on companies' business models? The research question is answered by examining a longitudinal, empirical case study which was part of the EU Horizon 2020 project. The current study examined how 10 companies developed new solutions in an ecosystemic open innovation in three countries. The aim of the Horizon 2020 project was to create a novel demand-driven innovation model to support co-creation between hospitals and e-health companies to enable companies to launch new digital health solutions for the healthcare industry market. A further target of the Horizon 2020 project is to adapt the innovation model to new industries in the future ${ }^{1}$. Open innovation and open business models have been widely debated in innovation research during the past decades (Chesbrough, 2003; Dahlander \& Gann, 2010; Gassmann \& Enkel, 2004; von Hippel, 2005; Prahalad \& Ramaswary, 2004; West \& Gallagher, 2006; Chesbrough 2017; Santoro et al., 2018). Some studies have been related to the benefits of open innovation (e.g., Laursen \& Salter, 2006), knowledge management and open innovation (e.g., Chesbrough 2003; Kian et al., 2015), the success of open innovation from an organisational perspective (Foss et al., 2011; Hienerth et al., 2011; Salge et al., 2012), as well as business models and open innovation (e.g., Chesbrough \& Schwartz, 2007; Hienerth, Keinz, \& Lettl, 2011; Keinz, Hienerth, \& Lettl, 2012; van der Meer, 2007). There have also been emerging studies on business models in an ecosystemic, open context (e.g., Iivari, 2016; Gomes et al., 2017a,b, 2018).

Although there are a few studies on open innovation and business models (see, e.g., Henkel et al., 2014; Saebi \& Foss, 2015) and some on open innovation in the healthcare context (see, e.g., Wass \& Wimarlund, 2016; Gabriel et al. 2017; Haukipuro et al. 2018), current research still lacks empirical knowledge on the impact of open innovation on company business models (Saebi \& Foss 2015). There is also not much research on how companies are co-creating e-health innovations with healthcare organisations. In 2015, Saebi \& Foss introduced a new theoretical framework about open business models, arguing that by adopting an open innovation strategy, companies could better identify external knowledge sources, integrate external ideas into their innovation processes as well as interact with external players in their network. Yun, Yang, and Park (2016) have proposed a framework for business model development in open business model

$1 \quad$ Main objectives: 1) to set up and validate a sustainable co-creation model that solves bottom-up challenges identified within public entities, 2) to increase the capacity of public entities for systematically identifying needs that can be converted into successful business opportunities for private companies. (Source: https: //cordis.europa.eu/project/rcn/211099/factsheet/en) 
environments. There is also much discussion in the existing literature about the definitions of a business model. Previous literature characterises a business model as a statement (Stewart \& Zhao, 2000), description (Applegate, 2000), representation (Morris, Schindehutte, \& Allen, 2005; Shafer, Smith, \& Linder, 2005), an architecture (Dubosson-Torbay, Osterwalder, \& Pigneur 2002), a conceptual tool or model (Osterwalder, Pigneur, \& Tucci, 2005), a structural template (Amit \& Zott, 2001), a method (Afuah \& Tucci, 2001), a framework (Afuah, 2004), and a pattern (Brousseau \& Penard, 2006). In this study, a business model is defined according to Amit \& Xott (2001): "as the content, structure, and governance of transactions designed so as to create value through the exploitation of business opportunities" (2001: 511). This is linked to the technical potential, which in our case works as a way to realise economic value (as described by Chesbrough \& Rosenbloom, 2002). In a dynamic environment, business models can no longer be static, focusing on one company perspective (Zott, Amit, Massa, 2011; Chesbrough, Vanhaverbeke, West, 2014). Business model research must focus on business models in a dynamic, turbulent environment with a mix of different players. Some researchers have described this as a coupled open innovation context (Chesbrough et al., 2006; Kim et al., 2014).

A new demand-driven coupled open innovation process was developed and piloted in the inDemand project (Malm and López, 2019). In this paper we examine how companies change their business modelling (i.e. value creation) in a demand-driven open innovation approach and the impacts of coupled open innovation on companies' business models. This paper presents the results of a two-year-long longitudinal study of demand driven open innovation. Our empirical setting specifically involves eleven organisations and altogether ten selected companies from Finland, France and Spain which aimed co-create e-health innovations for the healthcare market. Companies' new potential business opportunities were purely based on the collected needs of healthcare professionals in the healthcare organisations. Demand-driven needs were further developed during an intensive 7-month co-creation processes in the healthcare context. The companies and institutions (regional public and private healthcare organisations, intermediate organisations and funding organisations) co-developed new e-health innovations in the three pilot regions. Qualitative research was carried out using a longitudinal participatory case study method (e.g. Strauss and Corbin, 1990; Yin, 2013) in which interviews and surveys were collected in several intervals from all of the coupled open innovation partners in Finland, France and Spain during a two-year time period.

The paper contributes to the open business modelling literature by empirically testing the open business modelling framework introduced by Saebi \& Foss (2015). Through an analysis, we identified how companies change their business modelling in the coupled open innovation context. We assume that by using a new demand-driven coupled open innovation process, companies find the opportunity to co-create solutions and business models that better meet the needs of potential customers. The paper also introduces a new concept: a demand-driven open innovation model, in which customer needs are collected in a systematic process by the customer organisation. Using a structured selection process, a company is selected to co-create a new solution with sector-specific professionals with the aim of transforming the need into an economically viable business. Finally, the study results contribute to the implementation of knowledge management, with managerial recommendations for stakeholders interested in demand-driven open innovation, and the coupled network context. 


\section{Theoretical background}

\subsection{Business models}

Although business models have been researched in a large number of studies, most examine the business model of a local company and not from a network perspective (see Amit \& Zott, 2001; Weill \& Vitale, 2002; Chesbourgh \& Rosenbloom, 2002; Magretta, 2002, Chesbrough, 2003; Morris et al., 2005, Osterwalder et al., 2005, Shafer et al., 2005, Baden-Fuller et al., 2008; Teece, 2010; Onetti et al., 2012). Some authors, however, explore business model either from the value chain perspective (see Tapscott et al., 2000; Weill \& Vitale, 2002; Zott \& Amit, 2010), or the ecosystemic perspective (see Iivari, 2016; Gomes et al., 2017, 2018). Thus, although the business model has also been conceptualised in many research articles (see the list in Saebi \& Foss, 2015), the business model description is not clear (Zott, Amit, Massa, 2011). Magretta (2002) has defined business models as "stories that explain how enterprise works". A good business model answers Peter Drucker's (1994) questions: 'Who is the customer?' and 'What does the customer value?' It also answers the fundamental question every company must ask: 'What is the underlying economic logic that explains how we can deliver value to customers at an appropriate cost?' (See also Zott et al., 2011).

The business model concept has also concentrated on the domains of innovation and technology management. These are two complementary ideas that characterise the research in this field. The first is that through their business models, companies commercialise innovative ideas and technology. The second is that the business model itself represents a new subject of innovation which complements the traditional subjects of process, product, and organisational innovation requiring new forms of cooperation and collaboration (Zott et al., 2011). Both business and technological innovation could change a company's operational and commercial activities and the business model (for technological innovation see Calia, Guerrini, and Moura, 2007). Most of the studies claim that a business model is a way to create, deliver and capture value in the target market (Saebi \& Foss, 2015). In this study, a business model refers to the content, structure, and governance of transactions designed to create value through the exploitation of business opportunities which are linked to the technical potential and economic value.

\subsection{Open innovation}

Chesbrough (2003) introduced the idea of open innovation as a mode of innovation in which companies look outside their organisational boundaries in order to leverage internal and external sources of knowledge. One approach to obtaining benefits from open innovation is to do so through co-creation. A better business model can lead companies towards better technology outcomes (Chesbrough, 2007). Building a new business model is important for market access (see Table 1). Often, open innovation also requires the adoption of new open business models designed for sharing and licensing technologies (Chesbrough, 2007, 2010). Business models for co-creation need to be designed in such a way that external parties are allowed to participate in the company's specific activities and to modify product/service delivery processes in order to deal with the increased need for adaptation (Storbacka, Frow, Nenonen, Payne, 2012). 
Table 1. Closed versus open innovation (Chesbrough 2003, p. 38).

\begin{tabular}{ll}
\hline Closed innovation principles & Open innovation principles \\
\hline The smart people in our field work for us. & $\begin{array}{l}\text { Not all the smart people work for us, so we must } \\
\text { find and tap into the knowledge and expertise of } \\
\text { bright individuals outside our company. }\end{array}$ \\
\hline $\begin{array}{l}\text { To profit from R\&D, we must discover, develop } \\
\text { and ship it ourselves. }\end{array}$ & $\begin{array}{l}\text { External R\&D can create significant value; } \\
\text { internal R\&D is needed to claim some portion of } \\
\text { that value. }\end{array}$ \\
\hline $\begin{array}{l}\text { If we discover it ourselves, we will get it to } \\
\text { market first. }\end{array}$ & $\begin{array}{l}\text { We do not have to originate the research in order } \\
\text { to profit from it. }\end{array}$ \\
\hline $\begin{array}{l}\text { If we are the first to commercialise an } \\
\text { innovation, we will win. }\end{array}$ & $\begin{array}{l}\text { Building a business model is important for } \\
\text { market access. }\end{array}$ \\
\hline $\begin{array}{l}\text { If we create the most and the best ideas in the } \\
\text { industry, we will win. }\end{array}$ & $\begin{array}{l}\text { If we make the best use of internal and external } \\
\text { ideas, we will win. }\end{array}$ \\
\hline $\begin{array}{l}\text { We should control our intellectual property (IP) } \\
\text { so that our competitors do not profit from our } \\
\text { ideas. }\end{array}$ & $\begin{array}{l}\text { We should profit from others' use of our IP, and } \\
\text { we should buy the IP of others whenever it } \\
\text { advances our own business model. }\end{array}$ \\
\hline
\end{tabular}

Chesbourgh, Vanhaverbeke, West (2014; see also Chesbrough, 2017) define open innovation more broadly by also including a business model view as "a distributed innovation process based on purposively managed knowledge flows across organisational boundaries, using pecuniary and non-pecuniary mechanisms in line with the organisation's business model". The future of open innovation will extend beyond technology into business models. Open innovation will be more extensive and more collaborative, and there will be wider variety of participants (Chesbrough, 2017). Recently, Gomes et al. (2017a, b, 2018) suggested that each company should have sufficiently agile business models in the ecosystemic context in order to sense, seize and transform a company's capability to respond to the market needs. When a new business opportunity is available, the company's business model should also be reviewed and organised in a new manner.

\subsection{Knowledge as a driver for business models in open innovation}

Saebi \& Foss (2015) introduce a new framework for open businesses, integrating the two key concepts: open innovation and the business model. Saebi \& Foss (2015) also present three key driving concepts when evaluating company business models in open innovation: 1) the level of value co-creation 2) the type of knowledge flow and 3) the level of collaborative capability. They have also introduced four different open innovation strategies: a market-based innovation strategy, a crowd-based innovation strategy, a collaborative innovation strategy and a networkbased innovation strategy. In our study, we concentrate on a collaborative innovation strategy. When adopting a collaborative innovation strategy, the company chooses a designated knowledge partner for the co-creation process.

Co-creation has been widely used in recent literature to investigate customer relationships, stakeholder interactions, consumer centrism, co-design, self-service, co-production, relationship mar- 
keting and experiential marketing (Ranhan \& Read, 2016). Co-creation includes close interaction to facilitate the transfer and sharing of knowledge between parties (von Hippel, 2005; Saebi \& Foss, 2015). The most typical definition of value co-creation is that customers (in some cases consumers) play an active role in creating value together with the company (Ranhan \& Read, 2016). A collaborative innovation strategy business model needs to be centred on the development and delivery of often disruptive innovations and/or the creation of new target markets (Saebi \& Foss, 2015).

Different open innovation approaches require different levels of value co-creation related to the business models (Saebi \& Foss, 2015), i.e. how the value is created and how it is captured. In the cases of open business models, the potential for co-creation increases if companies can continuously gather information on the needs and feedback from the end users or customers and adjust their business models accordingly (Saebi \& Foss, 2015; Gomes et al., 2018). In the open business model, knowledge and innovations are jointly developed between the company and its customer (Saebi \& Foss, 2015). In the ecosystemic or network context (i.e. coupled open innovation), this means that both knowledge and innovation are developed not only between the customer and the company but between the customer, the company and the other ecosystem actors (universities, business development agencies, regional development agencies, etc.). In the collaborative open business model, the potential for co-creation becomes greater when knowledge and technologies are co-created (Saebi \& Foss, 2015).

Knowledge that promotes open innovation may lie anywhere in a company's value chain (Chesbrough, 2003). Companies should be open to ideas coming from different stakeholders in the value chain because it is the only way that new innovations can be elaborated. The knowledge flow is especially important from the open innovation perspective (Kian et al., 2015; Chesbrough, 2003). Open innovation research focuses on the direction of the knowledge transfer (inward, outward) and on companies' level of openness. Organisations should adopt proper organisational and managerial practices to effectively identify, manage, share, leverage and transfer internally and externally developed knowledge to support their competitiveness. There is still a lack of knowledge on management practice implementation to support the adoption of the open innovation paradigm (Alavi and Leidner 2001; Natalicchio, Ardito, Savino, Albino, 2017).

There are several approaches that define and classify knowledge management processes. According to McAdam \& Reid (2000), one way to define a knowledge management process is a model with four key dimensions: 1) knowledge construction, 2) knowledge embodiment, 3) knowledge dissemination, and 4) application of the knowledge. Knowledge construction could be the scientific view of knowledge, or it could be a social approach to knowledge. The critical questions include what is recognised as knowledge, and how such knowledge is developed in an organisation and its employees. In knowledge embodiment and dissemination, both scientific and social paradigms must be reflected in an attempt to embody and disseminate knowledge. In the application of knowledge, the most important point is the benefit to the whole organisation and its employees that it can bring about (learning, etc.) (McAdam \& Reid 2000, 317-318). Alavi and Leidner (2001, p. 110) propose that knowledge is a state of mind, a process, a condition of having access to information, or a capability. The perspective on knowledge as a state of mind means enabling the individual to expand personal knowledge and disseminate that knowledge. Knowledge viewed as an object demands that knowledge management focuses on building and managing knowledge 
stocks. Knowledge can also be viewed as a process of simultaneously knowing and acting. If knowledge is a process, knowledge management should focus on knowledge flows and the process of creating, sharing and distributing knowledge. (Alavi and Leidner, 2001) The fourth view of knowledge is that of a condition of having access to information. This view would also be seen as an extension of the view of knowledge as an object, with special emphasis on the accessibility of knowledge objects. Finally, knowledge can be viewed as a capability with a future aspect. The view of knowledge as a capability stems from the knowledge management perspective; centred on building core competencies, it considers the strategic advantage of knowledge management and creating intellectual capital. The important implication of these conceptions of knowledge is that each perspective suggests different kinds of knowledge management.

Knowledge management practices are often demanding, because knowledge is shared and managed by organisations with different cultures, structures and strategic orientations. It is important to manage knowledge so that everybody from different organisations can participate and improve an organisation's capability to share knowledge and avoid situations where only one or a few organisations are able to take advantage of it (Lichtenthaler, 2008; see also Natalicchio et al., 2017).Appropriate tools for knowledge sharing are needed. Additionally, framework conditions must be in place in which organisations engage the process of knowledge management. Faceto-face interactions are important, and information technology solutions may also be useful to sustain knowledge for the management of new technological solutions during the co-creation process (Esereyl, 2014). These management-related activities may include communication, coordination and participation of the co-creation participants.

Previous studies have classified open innovation practices and activities (Dahlander \& Gann, 2010; Enkel, Gassmann \& Chesbourgh, 2009; Natalicchio et al., 2017.) Three different processes have been discussed in the literature and these are: the inbound open innovation process, the outbound open innovation process, and the coupled open innovation process. The inbound process is characterised by knowledge flowing from the external environment to the organisation. The outbound process involves the flow of internally developed knowledge to the external environment. In the coupled open innovation process, the inbound and outbound processes are combined; and the open innovation process is a co-creation process with different organisations. (Dahlander \& Gann, 2010; Natalicchio et al., 2017.) By collaborating in the open innovation manner using open innovation processes, in the healthcare management context, the company ends up with a new strategy in which they are putting their efforts into the collaborative work and agreements with the different types of hospital management and users (Simard \& West, 2006; von Hippel, 2005). Companies have two strategies to choose from in utilising the knowledge gained from external parties. In collaborative and network-based innovation, innovation is developed closely with external parties so that the collaborative strategy relies on the other organisation (such as a hospital or a clinic) (Saebi \& Foss, 2015).

The level of collaborative capacity means the stakeholders need to interact with external knowledge providers. There is a need to develop collaborative capabilities concerning mutual knowledge exchange and development as well as managing a long-term partnership. Open innovation strategies have some shared organisational effects which are referred to as 'similar responses. Sometimes the adoption of open innovation strategies may evoke fear among the company's employees of losing competence, responsibility or even a job. For this reason, all open business 
models need to include appropriate incentives and control mechanisms to reduce fear and increase the commitment of employees to the open innovation practices of the company (Saebi \& Foss, 2015).

\subsection{Summary: Theoretical framework for collaborative business modelling in open innovation}

Saebi \& Foss (2015) presented a contingency model to clarify the business model continuum. The business model content includes value co-creation. In the collaborative, open business model, value co-creation includes aspects such as the development of radical innovations and opening new target segments. The business model structure is described by the type of knowledge flow. In the collaborative open business model, the type of knowledge flow is dyadic - every relevant stakeholder becomes a key partner in the innovation process. A dyadic knowledge flow also describes coupled open innovation, where knowledge flows inside and outside organisational boundaries. Business model governance is described by the level of collaborative capacity. In the collaborative open business model, the personnel participating in the innovation process must have the collaborative capacity to achieve success in open innovation. Business model governance in a collaborative, open business model is contract-based; it includes sharing rewards on the organisational level with an external knowledge provider. This dimension also includes incentives for employees to engage with users and other stakeholders in co-creation (Saebi \& Foss, 2015). The theoretical framework in this study is summarised in Table 2.

Table 2. Open innovation based business model framework (adapted from Saebi \& Foss 2015).

\begin{tabular}{cc}
\hline \multicolumn{1}{l}{ Business models } & Knowledge management \\
\hline Collaborative open business modelling: low - semi - high \\
\hline Business model content & Level of value co-creation \\
\hline Collaborative open business modelling: unilateral - dyadic - multilateral \\
\hline Business model structure & Type of knowledge flow \\
\hline Collaborative open business modelling: low - semi - high \\
\hline Business model governance & Level of collaborative capacity \\
\hline
\end{tabular}

\section{Research setting and methods}

To address the research question, a qualitative case study is presented based on 36 surveys, 26 interviews, 5 focus groups, and observations of healthcare professionals and companies that codeveloped new digital health solutions in hospitals, living labs and clinics. This chosen approach enabled the researchers to listen to healthcare professionals and company representatives. Both parties described how they had felt and experienced new way of innovating. Companies gave their insights into how they had experienced the hospital or a clinic as a potential customer and the key stakeholder in a large-scale EU-wide collaboration project as well as intermediate and funding organisations such as supporting stakeholders. 


\subsection{Empirical setting and context}

The research setting is the ecosystem of the inDemand project. The EU Horizon2020 inDemand project is a three-year-long project which aims to develop and test a new demand-driven, coupled, open innovation model. First the model will be tested in the healthcare sector to support co-creation between hospitals/clinics and companies. The target is to the further develop the innovation model in other sectors in the future. For the longitudinal study, three regional healthcare organisations (e.g. hospitals and clinics), one university, three business development organisations four regional development agencies, and ten awarded companies (in answer to 10 challenges proposed by the healthcare organisations) were selected. The companies were involved in the field of digital health and the pilot study involved regions in three countries: Finland, France and Spain.

A longitudinal participatory case study method was used, as one author has been part of the inDemand model framework development and actual implementation of the model. The demanddriven co-creation framework for the coupled open innovation was co-developed among international partner organisations in continuous interactive collaboration. The four active coupled open innovation stakeholders were assigned the following roles in the inDemand model development and application in the three regions.

Phase 1. Healthcare organisations were assigned the role of Challengersand focused on the demand-driven need identification process. The Challengers in Finland and Spain launched an internal call to identify unmet needs inside their organisations. In France, the Challenger organisation was a central procurement body who identified a private pilot hospital for the project. Healthcare professionals (nurses, medical doctors, etc.) proposed the most important current needs or problems they encounter while taking care of patients in their daily work routines or in hospital processes. Then hospital management teams evaluated the relevance of the proposed challenges to match the scope of the inDemand project. In two pilot regions, the hospital management teams aligned the proposed challenges to their overall hospital strategies. Through a systematic evaluation and selection process, ten challenges were selected to be the first iteration of the inDemand model application.

Phase 2. In collaboration with Challenger and Supporter (regional intermediate organisations) representatives, the Funders (regional funding organisations) selected the most suitable companies to be the Solversof the needs proposed by the healthcare professionals. For the company selection, the funding organisations prepared initial challenge descriptions with the Challengers and Supporters and published an EU-wide public call (open for 3 months) for SMEs ${ }^{2}$. The SMEs had the opportunity to evaluate the initial challenge descriptions and select which challenge could match their capabilities, know-how and skills. The Funders had received cascade funding from the European Commission to be transferred to the awarded companies: The call included an economic grant of approximately 30,000 euros for each selected SME to co-create new, demand-driven e-health solutions (www.indemandhealth.eu/indemand-model/).

SME: Eligibility criteria included legal status of the applicant must be a Small and Medium Enterprise compliant with the EU definition of SMEs. The SME's project proposal must be provided in English and address one of the Challenges in the public Call, using the e-health solution minimum Technology Readiness Level (TRL) 6 . 
Phase 3. After the inDemand project kick-off, the healthcare organisation and companies cocreated new e-health solutions together. The companies introduced several prototypes to the healthcare organisation and received continuous feedback from the healthcare professionals. The Supporters facilitated the co-creation projects from the company perspective. They also delivered tailor-made business support to the awarded companies in terms of business model generation, access to finance and access to markets. At the end, companies reported the co-created results to the Challenger management and funding organisations, and the Funders released the final payment. The Challengers' innovation management, together with the Challengers' top management, evaluated the co-created results and decided which companies would continue the solution development work after the inDemand project.

\subsection{Data collection}

From a validation perspective, it was important to conduct data collection similarly in all of the pilot regions. This allows the researchers to study regional differences and practices that will eventually be fed into the internal and external inDemand model validation. The collected data consists of 36 surveys and 26 semi-structured interviews of healthcare professionals and companies as well as 5 focus group interviews and observations, email communications and meeting memos in the three pilot countries. All the data was collected by a researcher with a help of Supporter and Challenger in Finland, and by Supporters and Challengers in France and Spain.

In the first phase, the expectations related to the open innovation were asked from the participants using an expectation survey (see Appendix 1). The first data, from the expectation surveys, was collected via an online questionnaire before the co-creation project had fully started. The expectation surveys were sent to be reviewed and completed by all the stakeholders of the project. The second part of the data was also gathered via short online questionnaires during the co-creation phase and in a prototype presentation meeting in the middle of the co-creation projects (Appendix 2). The third part of the data collection included two steps. First, faceto-face focus group interviews with regional Challengers, Supporters and Funders in their own groups were carried out, each lasting approximately 80 minutes. A co-creation results interview with companies and healthcare professionals at the end of the co-creation process took between 30 and 80 minutes. Before this interview, the researchers spent approximately 30 hours defining appropriate thematic questions that were in line with the theoretical framework and current practical understanding of the inDemand model application. All interviews were recorded and transcribed (Finnish-English, French-English, and Spanish-English), see Table 3.

\subsection{Data analysis}

Case study research can be used in the situations in which we are examining the contemporary phenomenon in its real context and multiple sources of evidence is used (Yin 2003). For the data analysis, all the interview transcriptions were read carefully, divided, and categorised into themes built up from earlier research. In line with Straus \& Corbin (1990), the interview transcripts were read individually and identified by codes (i.e. specific words and statements pointing to a 
Table 3. Interview informants. Source: the authors' own.

\begin{tabular}{lcc}
\hline Informant & Length & Date \\
\hline Company (CB1) 1, Country B & $48 \mathrm{~min}$. & $\mathrm{Nov} / 2018$ \\
\hline Company (CB2) 2, Country B & $43 \mathrm{~min}$. & $\mathrm{Nov} / 2018$ \\
\hline Company (CB3) 3, Country B 2 persons & $80 \mathrm{~min}$. & $\mathrm{Dec} / 2018$ \\
\hline Company (CB4) 4, Country B & $62 \mathrm{~min}$. & $\mathrm{Dec} / 2018$ \\
\hline Company (CC1) 1, Country C & $43 \mathrm{~min}$. & $\mathrm{Jan} / 2019$ \\
\hline Company (CC2) 2, Country C & $66 \mathrm{~min}$. & $\mathrm{Jan} / 2019$ \\
\hline Company (CC3) 3, Country C & $41 \mathrm{~min}$. & $\mathrm{Feb} / 2019$ \\
\hline Company (CC4) 4, Country C & $43 \mathrm{~min}$. & $\mathrm{Feb} / 2019$ \\
\hline Company (CA1) 1, Country A & $43 \mathrm{~min}$. & $\mathrm{Jun} / 2019$ \\
\hline Hospital professional (HB1) 1, Country B & $28 \mathrm{~min}$. & $\mathrm{Nov} / 2018$ \\
\hline Hospital professional (HB2) 2, Country B & $32 \mathrm{~min}$. & $\mathrm{Nov} / 2018$ \\
\hline Hospital professional (HB3) 3, Country B & $39 \mathrm{~min}$. & $\mathrm{Nov} / 2018$ \\
\hline Hospital professional (HB4) 4, Country B & $53 \mathrm{~min}$. & $\mathrm{Nov} / 2018$ \\
\hline Hospital professional (HC1) 1, Country C & $47 \mathrm{~min}$. & $\mathrm{Apr} / 2019$ \\
\hline Hospital professional (HC2) 2, Country C & $31 \mathrm{~min}$. & $\mathrm{Mar} / 2019$ \\
\hline Hospital professional (HC3) 3, Country C & $46 \mathrm{~min}$. & $\mathrm{Apr} / 2019$ \\
\hline Hospital professional (HC4) 4, Country C & $51 \mathrm{~min}$. & $\mathrm{Apr} / 2019$ \\
\hline $\begin{array}{l}\text { Focus group Supporters 4 persons (S) (A, B, C) (3 countries one } \\
\text { person, one country 2 persons) }\end{array}$ & $52 \mathrm{~min}$. & $\mathrm{Nov} / 2018$ \\
\hline $\begin{array}{l}\text { Focus group Challenger representatives (CR) (A, B, C) 3 persons } \\
\text { (all countries 1 person) }\end{array}$ & $78 \mathrm{~min}$. & $\mathrm{Nov} / 2018$ \\
\hline $\begin{array}{l}\text { Focus group Funders 3 persons (F) (A, B, C) (all countries 1 } \\
\text { person) }\end{array}$ & $58 \mathrm{~min}$. & $\mathrm{Nov} / 2018$ \\
\hline & & \\
\hline
\end{tabular}

theme). Due to the number of partners (11) and companies (10) involved, we collected qualitative information and insights on the co-creation expectations and experiences.

The semi-structured format of the interviews allowed the interviewees to discuss and describe the issues that were important to them. Indeed, especially with the results interview with companies, this proved to be helpful in finding important topics in the emerging themes and also the data saturation point to complete this study. The emerging topics included aspects such as the hospital as an end-customer, the procurement process, and securing adequate resources for both companies and healthcare organisations in open innovation projects, as well as companies' attitudes towards the inDemand model concept etc. The participatory case study approach encouraged a second iteration in the application of the inDemand model. Finally, the precise research focus developed during the data collection and analysis phases. 


\section{Empirical findings}

\subsection{E-health innovation in the coupled open innovation environment}

The expectation surveys revealed that companies' greatest challenges in their past collaboration with the public sector were (1) slow decision-making, (2) lack of support from the hospital IT department, and (3) how to monetise the project results after the pilot. However, a structured and pre-scheduled co-creation process enabled companies to have a more structured and firm approach in their new product development projects. During the 7-month co-creation process, companies learned how to work in the healthcare environment and how to speak the same language with their potential customers. The companies reported that the co-creation process helped them to keep focused on the most important aspects when developing new solutions in the complex healthcare market.

\subsection{Business model content}

In the collaborative open business model, the co-creation included the development of radical innovations and opening new target markets. Each of the 16 company representatives (e.g. CEOs, product managers, business development managers) reported that the healthcare organisation as an end-customer would be an expected end result. Twelve company representatives stated that new products and features, a faster entry to market and a route to international markets were the most important expectations and benefits of the co-creation process for business development. Companies expected that co-creation develops their current businesses by getting access to the new business sector care pathways, product development and achieving a better understanding of customer and patient demands.

The analysed data showed that companies need to be flexible when adhering to the hospital code of conduct and data protection procedures. They need to plan and utilise their resources effectively. Companies also need to devote time to understanding the new, demand-driven cocreation process, as stressed by one healthcare professional who stated: "And then, be sure that Solvers have clearly understood their role... not to consider the hospital as a customer as usual. They really have to work together in order to co-create and to accept this new (demand-driven co-creation) methodology." Despite the necessary learning curve, the companies appreciated the tested concept, because it included a structured means of solution development with an interested end-customer. However, the co-creation process was very time-consuming for the companies. As one company stated, one reason was that a hospital development team did not have a unified view of the most important functionalities for the new solution. In this case, the needs identification process was inadequate, causing unnecessary delays later in the technical solution development.

The co-creation of value was on multiple levels because different stakeholders supported the co-creation between the two core developers - hospitals and companies. The Funders facilitated the new business development with a grant. The Supporters focused on tailor-made business development support; companies were required to prepare a go-to-market plan to enhance the commercialisation process (e.g. customer validation, pricing, earning logic, internationalisation 
opportunities), even though companies had not yet officially launched their new solutions onto the market (i.e. value capture had not yet been actualised in monetary terms). In this respect the companies stated that co-creation in the coupled open innovation context facilitated future value-capture in their business models. As one of the interviewees noted:

The Supporter is the one who helps us, the company. Both in communicating with the Challenger, as well as publicising the tool, also in other fields, with other people who aren't Challengers and who advise us on how to reach other places.... When the developers talk about the tool (i.e. the co-created solution), they're aware at all times that it's a combined effort of the whole team-the Challenger, the developers, the Supporter and everyone else.

Another company representative continued by stressing the importance of the business development focus as part of the co-creation process: "The innovation is very good, but if you don't enter the market, it has no value...here... it is a mix of almost putting it on the market or being able to sell having tried it out with real users, which is good for inDemand, isn't it? ... the key factor..."

With regards to the value creation process, companies highlighted that demand-driven cocreation was a valuable and practical start for new business opportunity recognition. In this respect, one of the interviewees noted: "It's of course a competitive advantage that there's proofbased and research-based information that's been produced by healthcare professionals. It's quite a big competitive advantage that this is the starting point." Another company representative highlighted the importance of achieving a reference from the healthcare organisation after the successful co-creation experience: Working with the hospital which has made us a first recommendation, is valuable in putting us amongst the others.'

\subsection{Business model structure}

Knowledge-based value creation was actualised in various interactive dialogues (e.g. face-to-face meetings, electronic workspace, Slack tool, Skype calls, meeting memos, follow-up calls, emails). Most companies were regularly invited to the hospital or clinic for group meetings and one-on-one workshops with multidisciplinary healthcare professional teams and IT department specialists. Companies received valuable feedback at each stage (e.g. prototypes and testing) of the product development. One company representative stated: "We use every channel of communication." The co-creation results interviews with companies revealed that successful co-creation was based on a continuous flow of communication. For example, one of the representatives noted that: "Now (also) in the piloting phase, they call us from time to time to ask how things are going... they include us well in the process." The data also included one company which reported that some healthcare professionals did not have adequate communication tools (i.e. Skype access, their own work computers), making the dialogue and product development slower.

\subsection{Business model governance}

Developing an innovation in a demand-driven open innovation context requires collaborative capacity. When describing how companies' normal processes of innovation differed from the 
demand-driven co-creation approach, a company representative described how they experienced demand-driven open innovation: "We could say that in our usual projects we are in a techno push, clearly,... But once we were chosen (for this project), it was more about the subject of needs. The doctors' needs".

Open innovation projects were perceived as attractive because they provided "... a framework of openness, meaning working with people who are motivated to share things". Furthermore, one of the interviewees stated: "Going back to inDemand's logic, this is what opens doors, and I think this is mutually beneficial. We've had the resources to define a solution calmly and cleanly that responds to needs, from the first user... a solution that ticks all their boxes... the opening of and the ability to have a dialogue is beneficial from our point of view." Additionally, a company representative defined their view of open innovation: "We are of the logic that for the work to succeed we have to build consortiums with common interests and accept that we share making the pathway with them and the rest of the staff in order to profit from it... without specific borders between big and small, or between private and public."

One company representative reported that the mutual knowledge exchange had not succeeded in terms of what is meant by co-creation in an innovation process. Consequently, the level of collaborative capacity in their view had not developed. This person stated:

We could say that in the management area, we've understood each other well... but on the part of the clinicians, it seemed like it was their project and that they ruled over it. There were even occasions in which they acted as if we had stolen their project, when in fact we came to the project with experience in the same field they were going to work in. In other words, we were there before they were.

The healthcare professionals carried out the co-creation projects in addition to their daily work routines, without any additional economic compensation. They understood their value and were motivated by being able to influence their work by objectively describing their workflow and routines and how to improve them. For example one of the respondents noted: "The schedule is very challenging,... We're doing it besides other work... We've received ideas and we've changed things, and as we've changed the contents, the companies have been active and they've asked about and changed things that we've informed them about. And they've listened to development suggestions from the point of view of the clinic and the hospital, so I'm satisfied."

\section{Discussion}

Next, managerial implications of this case study are discussed. Traditionally, companies have used a technology-push model, where the main motivator for new product development has usually arisen from technology (IT solution, algorithm, technical system, etc.). With the demanddriven approach, the companies'search for a new business opportunity starts with the needs arising from a particular sector.

The results of the empirical investigation proved showing the most important impacts of coupled open innovation on the companies' business models are summarised in Figure 1. These impacts are: 1) that companies need to change their business model (i.e. value creation process) in the 
demand-driven open innovation approach; 2) that demand-driven co-creation gives companies valuable access to deep, field-specific data, information, practices and knowledge; 3) that the demand-driven coupled open innovation process can offer new business opportunities to companies; 4) utilising knowledge management together with open business modelling leads companies to fact-based value-creation (which helps companies to speed up their commercialisation processes and better meet the actual needs of the specific market); and 5) that the demand-driven, coupled, open innovation model can provide one practical framework in the challenging task of exploring economically viable new business opportunities in the knowledge economy.

\section{Impacts of open innovation on company business models}

Companies need to change their business models (i.e. value creation process) in the demand-driven open innovation approach. The search for a new business opportunity starts with the needs arising from a particular sector.

Demand-driven co-creation gives companies highly valuable access to deep, field-specific data, information, practices and knowledge.

The demand-driven, coupled, open innovation process can offer new business opportunities to companies.

Utilising knowledge management together with open business modelling leads companies to fact-based value-creation. This enhances companies' ability to speed up their commercialisation processes and better meet the actual needs of the specific market.

The demand-driven, coupled, open innovation model can provide one practical framework in the challenging task of exploring economically viable new business opportunities in the knowledge economy.

Fig. 1. 5 impacts of open innovation on company business models. Source: the authors' own material.

These impacts enabled companies to better understand the customer segments. Especially in the healthcare sector, the customers and users are typically different; the paying customer could be the innovation department, the central purchasing body, or the field-specific clinical department using the e-health solution. The users may be nurses and medical doctors in clinical departments and/or patients, their families and relatives. Better customer segment understanding facilitates building stronger value propositions and potential revenue streams from each customer segment. Intermediate organisations providing business support are encouraged to leverage their regional ecosystem resources to offer tailor-made business support to companies, as companies are at different stages of their lifecycle with varying needs. The support can take different forms, from individual to group coaching. As an example, classical tools such as the lean canvas/business model canvas (Ostelwalder, A. Pigneur, Y. 2010) are still useful in crystallising the lessons learned from co-creation and transforming them to the open business model. The go-to-market planning process ensures that business development activities are activated during the co-creation process; not all of the time is dedicated to technical solution development. Ultimately, it is the 
responsibility of the company to transform customer needs into a scalable business model. Table 4 summarises the key results of the study mapped with the theoretical framework.

\subsection{Business model content and multi-level co-creation in the ecosystemic context}

The coupled, open innovation process refers to a co-creation process in which companies work in an alliance in cooperation with other organisations, e.g., lead users that can be crucial for company success (Enkel et al., 2009). So far, there is not much research about network-level co-creation in which the network forms include consortia, ecosystems and platforms that require companies to orchestrate joint value creation and value capture of the firm across the network (West \& Bogers, 2017). In our case, stakeholders involved in coupled open innovation needed to learn new ways of working and had to ensure that co-creation was together accepted as a working method. A properly conducted demand-driven, needs identification process creates a path for companies to move towards more knowledge-based value creation and business modelling, mirroring a real-life setting. This is the basis of value co-creation and the key starting point for co-creation. According to an earlier study by Enkel et al. (2009), community participation can help companies to draw their customers, suppliers and other partners to the heart of their solution development, allowing them to interact with different players, which can then be used to reduce the risks related to business uncertainty. In our case study, sector-specific professionals had a positive impact on new product development, thus taking part in the creation of new business models. Hidden, field-specific knowledge and practical, hands-on work experience bring value to the co-creation process. Multidisciplinary teams enhance coupled open innovation projects. Field-specific professionals become innovators and early adopters of new solutions. In the case study of this paper, to ensure the smooth practical operation of demand-driven co-creation projects, it was important that the Challenger organisations' innovation management departments worked closely with their development teams to guide them in the collaboration with the companies.

In our study, it was proved that the community-based approach can be used to support change in the way value is created for companies; it changed from the traditional technology-push model to a demand-driven co-creation model. Demand-driven co-creation requires that companies build a new co-creation mindset, instead of selling to healthcare organisations. In the demand-driven cocreation process, companies are given an opportunity to work with potential end-customers and end-users, who in healthcare are typically different in a real-life setting. It enhances building a competitive advantage, differentiating the company from its competitors, and building new solutions based on sector-specific, knowledge-based information. The companies in this study believed that co-creation in the coupled open innovation context would facilitate future valuecapture in their business models.

\subsection{Business model structure and managing knowledge for value creation}

The success of knowledge flows or knowledge transfer in open innovation ecosystems is a topic that is still inconsistent in the current literature (Bacon et al., 2019). In our case, it became 
Table 4. Summary of the case study results. Collaborative open business modelling framework fact-based value-creation. Source: The authors' own material.

\section{Business model content}

- Companies work in alliance with other organisations towards joint value creation.

- Business model content development starts with a need from a healthcare organisation, followed by an adequate problem definition.

- Companies must orchestrate joint value creation across the ecosystem network.

- Companies need to develop a co-creation mindset and use their resources efficiently.

- Companies get access to healthcare organisation code of conduct \& data protection procedures enhancing solution relevancy.

\section{Multi-level co-creation in the ecosystemic context}

- Field-specific professionals become innovators and early adopters of new solutions.

- Regional funders lower the threshold for companies to participate through grants.

- Intermediate organisations support the co-creation between hospitals and companies. They offer tailor-made business support with business modelling, access to funding and access to markets by leveraging the ecosystem (e.g. networks, tools, coaching, and mentoring)

- The potential for multi-level co-creation becomes greater when knowledge, technologies, and business model are co-developed.

\section{Business model structure}

- Business model structure described by the type of knowledge flow.

- Companies need to manage new knowledge from different stakeholders in order to transform customer needs into a new business model in an iterative process.

\section{Knowledge-based value creation}

- Enabled by a structured demand-driven co-creation process.

- The potential for co-creation success increases with agile, continuous knowledge flow and transfer of knowledge (e.g. prototypes, testing, results) via different communication channels. This is strengthened by face-to-face workshops in a real-life environment.

\section{Business model governance}

- Business model governance in a collaborative open business model is contract-based (agreements, IPR) and includes sharing rewards on the company level with an external knowledge provider, e.g. healthcare organisation.

- Companies and field-specific professionals expect that co-created solutions are taken into use. This requires development of adoption strategies for the co-developed solutions.

\section{Level of collaborative capacity}

- All ecosystem stakeholders need to develop collaborative capabilities for knowledge exchange and success in open innovation projects

- Collaborative capacity requires adequate resources (personnel and budget) to ensure sustainable, impactful innovation development creating value for the company and the surrounding ecosystem. 
evident that different types of knowledge flow influenced how the solution was developed and what the result would be. Interactive, trustworthy, continuous communication and a knowledge flow via different communication channels was required. Regular communication and face-to-face meetings in a real-life environment were crucial and irreplaceable for the success of the community type of co-creation projects. An empirically tested co-creation approach with a structured framework supports dialogue between companies and healthcare organisations. Companies need to manage new knowledge sources from different stakeholders and must be able to transform customer needs into a new business model through an iterative process. To ensure a sustainable co-creation process, ideally, healthcare organisations and companies should determine the length of the co-creation project during the more detailed need identification phase; otherwise, the communication flow may be disrupted while the goals of the project have not yet been achieved.

It is important that innovation management departments (in healthcare organisations) have enough resources (e.g. a basic budget for demanding innovation activities, adequate human resources and communication tools) to work closely with the healthcare development teams and companies. Finally, healthcare professionals need guidance on how to collaborate with companies, as they are often not accustomed to working with outside companies.

\subsection{Business model governance requires collaborative capacity}

Business model governance in a collaborative, open business model is contract-based and includes sharing rewards on the organisational level with an external knowledge provider (Saebi \& Foss 2015). Aligned with the companies' view, the healthcare professionals in this study expected that they could take the developed e-health solutions into use. This required that the Challenger organisations should develop an adoption strategy for the new innovations, and formal, written procurement contracts need to be in place before the actual co-creation project starts.

The reality today is that public healthcare organisations perform innovation activities as a project-based activity, which means that innovation managers often lack adequate resources in terms of personnel and budget. Thus, hospital innovation management units are encouraged to build a yearly basic budget for innovation management activities to ensure sustainable, continuous innovation development. It is also suggested to build a compensation model for healthcare professionals engaging in intensive innovation projects in order to ensure their interest in intensive projects.

\section{Limitations of this study}

This study concentrated on company value creation through a demand-driven co-creation process. The limitations of this study derive from the fact that there is no longitudinal information yet available on how well the companies which participated in the study will be able to transform the results of the demand-driven creation (newly developed digital e-health solutions) into economically viable businesses, in two to three years'time. 


\subsection{Recommendations for future research}

A longitudinal research approach enables monitoring how the new solutions developed by the participating companies will have succeeded in the complex healthcare market, after a few years' time, and the value-capture could then be evidenced. However, this study is showing only the initial results of the longitudinal study that will be finished and published later looking at the open innovation and co-creation from the different perspectives. For instance, there is a need to understand what is the long term impact of demand driven open innovation for healthcare providers and policy makers. Furthermore, there is a need to enhance the sustainability of the demand-driven co-creation model at the policy level and in the other sectors. Indeed, an innovative procurement and adoption strategy for the co-created solutions in the Challenger organisations is required for the sustainability of the innovation model, as it is also a prerequisite for the replicability of the model in new industries. One potential future research angle for the study is to look at how to replicate the similar model in the selected mirror regions and what are the different micro level practices to be taken into use in different regional ecosystems and why.

This paper contributes to the knowledge management and open business model literatures (e.g., Keinz, \& Lettl, 2011; Keinz, Hienerth, \& Lettl, 2012; van der Meer, 2007) by proposing a concept for a demand-driven, open innovation model. This study provides empirical knowledge on the impact of coupled open innovation on company business models. Managerial implications facilitate the practical adoption of (coupled) open innovation projects and open business modelling in the demand-driven, open innovation context. The demand-driven, co-creation approach provides a framework to improve knowledge management practices among different organisations in today's complex, turbulent environments. With the demand-driven, needs identification process, a step towards knowledge-based value creation and business modelling can take place. This is because the demand-driven co-creation approach allows an interactive and iterative dialogue between the company and the challenger organisation.

\section{Conclusion}

In this paper, we evaluated the impacts of coupled, ecosystemic, open innovation on companies' business models. We conclude that companies need to change their business modelling process (i.e. value creation process) in the demand-driven open innovation approach. It became evident that demand-driven co-creation gives companies highly valuable access to deep, sector-specific data, information, practices and knowledge. The demand-driven, coupled open innovation process can offer new business opportunities to companies. Utilising knowledge management together with open business modelling leads companies to fact-based value-creation. This allows companies to speed up their commercialisation processes and better meet the actual needs of the specific market. The demand-driven, coupled open innovation model can provide a practical framework in the challenging task of exploring economically viable new business opportunities in the knowledge economy. Companies are highly motivated to take part in solving global healthcare challenges to improve quality, patient care and cost efficiency in the healthcare industry. 
Acknowledgements. We thank the European Commission for the inDemand project funding from the European Union's H2020 Programme, SC6-CO-CREATION-2016-3, for research, technological development, and demonstration (Grant Agreement no 763735). We thank the inDemand Consortium members for taking part in the data collection in the pilot regions and Timo Alalääkkölä, Pauliina Hyrkäs, Elena López, Romain Vallée for helpful comments in the finalization of this paper.

Conflicts of Interest. The funders of the project had no role in the design of the study; in the collection, analyses, or interpretation of data, in the writing of this manuscript nor in the decision to publish the results.

\section{References}

Afuah, A. (2004) Business models: A strategic management approach. New York: Irwin/McGrawHill. Afuah, A., \& Tucci, C. L. 2001. Internet business models and strategies: Text and cases. New York: McGraw-Hill.

Alavi, M. \& Leidner, D.E. (2001) Knowledge Management and Knowledge Management Systems: Conceptual foundations and research issues. MIS Quarterly, Vol. 25, Issue 1, pp. 107-136.

Amit, R., \& Zott, C. (2001) Value creation in e-business. Strategic Management Journal, Vol. 22: pp. 493-520.

Applegate, L. M. (2000) E-business models: Making sense of the Internet business landscape. In G. Dickson \& G. DeSanctis (Eds.), Information technology and the future enterprise: New models for managers: 49-101. Englewood Cliffs, NJ: Prentice-Hall.

Bacon, E. Williams, M.D., Davier, G.H. (2019) Recipes for success: Conditions for knowledge transfer across open innovation ecosystems, International Journal of Information Management, Vol. 49 , pp. $377-387$

Brousseau, E., \& Penard, T. (2006) The economics of digital business models: A framework for analyzing the economics of platforms. Review of Network Economics, 6(2): pp. 81-110.

Chesbrough, H. (2003) Open Innovation. Harvard University Press, Cambridge, MA.

Chesbrough, H. W., \& Rosenbloom, R. S. (2002) The role of the business model in capturing value from innovation: Evidence from Xerox Corporation's technology spinoff companies. Industrial and Corporate Change, Vol. 11: pp. 533-534.

Chesbrough, H., Vanhaverbeke, W., West, J. (2014) New frontiers in open innovation, Print ISBN-13: 9780199682461, Published in Oxford Scholarship Online: December 2014, DOI: 10.1093/acprof:oso/9780199682461.001.0001

Chesbrough, H. (2017) The Future of Open Innovation. The future of open innovation is more extensive, more collaborative, and more engaged with a wider variety of participants. Research Technology Management, Volume 60, Issue 6.

Chesbrough, H. (2006) Open Business Models: How to thrive in the New Innovation Landscape. Harvard Business School Press, Boston. 
Chesbrough, H. (2007) Business model innovation: It's not about technology anymore. Strategy and Leadership, 35 (6), pp.12-17.

Dahlander, L., \& Gann, D.M. (2010). How open is innovation? Research Policy, Vol. 39 (6), pp. 699-709.

Dubosson-Torbay, M., Osterwalder, A., \& Pigneur, Y. (2002) E-business model design, classification, and measurements. Thunderbird International Business Review, Vol. 44(1): pp. $5-23$.

Enkel, E., Gassmann, O., Chesbrough, H. (2009) Open R\&D and open innovation: exploring the phenomenon, R\&D Management, 2009, Vol. 39: Iss. 4.

Eseryel, U. Yeliz (2014) IT-Enabled Knowledge Creation for Open Innovation. Journal of the Association for Information Systems, Vol. 15: Issue 11.

Gassmann, O., \& Enkel, E. (2004) Towards a Theory of Open Innovation: Three Core Process Archetypes. R\&D Management Conference (RADMA), Lisbon, Portugal.

Gomes, J.F., Iivari, M., Ahokangas, P., Isotalo, L., \& Niemelä, R. (2017a) Cybersecurity Business Models for IoT-Mobile Device Management Services in Future Digital Hospitals. Journal of ICT Standardisation, Vol. 5(1), pp. 107-128.

Gomes, J.F., Pikkarainen, M., Ahokangas, P., \& Niemelä, R. (2017b) Towards business ecosystems for connected health. Finnish Journal of eHealth and eWelfare, Vol. 9(2-3), pp. 95-111.

Gomes, J.F., Iivari, M., Pikkarainen, M., Ahokangas, P. (2018) Business Models as Enablers for Ecosystemic Interaction: A Dynamic Capability.

Haukipuro, L., Väinämö, S., Hyrkäs, P. (2018) Innovation Instruments to co-create needs-based solutions in a living lab. Technology Innovation Management Review, Vol. 8, Issue 5, pp. 23-36, http://doi.org/10.22215/timreview/DDDD.

Henkel, J., Schöberl, S., Alexy, O. (2014). The emergence of openness: How and why firms adopt selective revealing in open innovation. Research Policy, 43, pp. 879-890.

lpay, Laurence \& Blanson, Henkemans, Olivier \& Otten, Wilma \& Rövekamp, Ton \& Dumaij, A. (2010) E-health Applications and Services for Patient Empowerment: Directions for Best Practices in The Netherlands. Telemedicine journal and e-health: the official journal of the American Telemedicine Association. 16. 787-91. 10.1089/tmj.2009.0156.

Iivari, M.M., Ahokangas, P., Komi, M., Tihinen, M., \& Valtanen, K. (2016) Toward ecosystemic business models in the context of industrial Internet. Journal of Business Models, 4(2).

Lichtenthaler, U. (2008) Relative capacity: Retaining knowledge outside a firm's boundaries. Journal of Engineering and Technology Management, Vol. 25 Issue 3, pp. 200-212.

Malm, H. \& López, E. (2019) inDemand deliverable report: D5.1 Co-creation and business support of the first inDemand Model iteration. https://www.indemandhealth.eu/cocreation_ business_support_report/

Morris, M., Schindehutte, M., \& Allen, J. (2005) The entrepreneur's business model: Toward a unified perspective. Journal of Business Research, Vol. 58: pp. 726-35. 
Ostelwalder, A. \& Pigneur, Y. (2010) Business model generation: a handbook for visionaries, game changers, and challengers, John Wiley.

Osterwalder, A., Pigneur, Y., \& Tucci, C. L. (2005) Clarifying business models: Origins, present and future of the concept. Communications of the Association for Information Science (CAIS), Vol. 16: pp. 1-25.

Osterwalder, A. 2004. The business model ontology - A proposition in a design science approach. Dissertation 173, University of Lausanne, Switzerland.

Prahalad, C. K., \& Ramaswary, V. (2004) Co-creating unique value with customers. Strategy and Leadership, Vol 32, No. 3.

Ranjan, K.R. \& Read, S.J. (2016) Value co-creation: concept and measurement. iJournal of the Academy of Marketing Science, Vol. 44, No. 3, pp. 290-315, https://doi.org/10.1007/ s11747-014-0397-2i.

Rodet-Kroichvili, N., Cabaret, K., Picard, F. (2014). New insights into innovation: the business model approach and Chesbrough's seminal contribution to open innovation. De Boeck Supérieur: Journal of Innovation Economics \& Management. 2014/3 \#15 (79-99).

Santoro, G., Ferraris, A., Giacosa, E., Giovando, G. (2018). How SMEs engage open innovation: a survey. Journal of the Knowledge Economy, Vol. 9, No. 2, pp. 561-574.

Saebi, T., Foss, N. (2015). Business models for open innovation: matching heterogeneous open innovation strategies with business model dimensions, European Management Journal, Vol. 33, No. 3, pp. 201-213.

Seelos, C., \& Mair, J. (2007) Profitable business models and market creation in the context of deep poverty: A strategic view. Academy of Management Perspectives, Vol.21: pp. 49-63.

Shafer, S. M., Smith, H. J., \& Linder, J. 2005. The power of business models. Business Horizons, Vol. 48: pp.199-207.

Silvi J. (2015). Here, there, everywhere - The rise of open innovation in healthcare. GE LookAhead, February 13, 2015.

Storbacka, K., Frow, P., Nenonen, S., \& Payne, A. (2012) Designing business models for value creation. In S.L. Vargo \& R.F. Lusch (Eds.) Special Issue - Toward a Better Understanding of the Role of Value in Markets and Marketing. Review of Marketing Research 9, 51-78.

Strauss, A. \& Corbin, J.M. (1990) Basics of qualitative research: Grounded theory procedures and techniques. Newbury Park Sage.

Stewart, D. W., \& Zhao, Q. (2000) Internet marketing, business models and public policy. Journal of Public Policy and Marketing, Vol. 19: pp. 287-296.

von Hippel, E. (2005) Democratizing Innovation. MIT Press, Cambridge, MA.

Wass, S. \& Vimarlund V. (2016). Healthcare in the age of open innovation - A literature review. Health Information Management Journal, Vol. 45 (3), pp. 121-133.

West, J. \& Gallagher, S. (2006). Challenges of open innovation: The paradox of firm investment in open-source software. R\&D Management, Vol. 36 (3), pp. 319-331. 
West, J. \& Bogers, M. (2017) Open innovation: current status and research opportunities, Innovation, 19:1, 43-50, DOI: ii10.1080/14479338.2016.1258995

Yin, R.K. (2003). Case Study Research: Design and Methods, $3^{\text {rd }}$ edition. Sage. Thousand Oaks, California.

Yun, J.J., Yang, J., Park, K., (2016). Open innovation to business model: New perspective to connect between technology and market. Science, Technology \& Society 21:3 (2016): 1-25

\section{Appendix 1 Research Instruments}

Copyright (C) University of Oulu 2018

In the beginning of the project: Expectation Questionnaire (for Challengers, Solvers, Supporters, Funders)

\section{inDemand questionnaire for Challengers}

Innovation process and innovation co-creation The aim of this questionnaire is to explore two main areas: first, how your organisation acquires and develops innovations for internal use at the moment, and second, how your organisation currently collaborates with partners and customers in relation to developing innovations. The questionnaire contains a number of questions which have been thematically categorised under three main approaches described below. Please keep these guidelines in mind when answering the questions

1 Where are we now? What are the current innovation development practices in the organisation at the moment? How does your organisation collaborate with private sector and other external stakeholders at the moment?

2 What will be different in the future? What expectations does your organisation have concerning demand-driven needs identification and innovation development? What expectations do you have for collaboration and co-creation using inDemand?

3 Impacts and implications What is the expected impact of inDemand and what implications will it have for the general innovation process in your organisation? What implications does the inDemand model have for co-creating and developing innovations together with the private sector?

Background questions (mandatory questions) Name, Organisation, The size of organisation, Role in the organisation, Role in the inDemand co-creation process

\section{Current practices in innovation development}

- Please describe how your organisation currently develops or acquires new products and services. (E.g. developed internally, acquired from internal partners, e.g. a subsidiary or from external providers. What is the decision-making process? Who can suggest needs for new solutions? How long is the process?)

\section{Current ways to collaborate and co-create with external stakeholders}

- How does your organisation currently collaborate with the private sector and other stakeholders in innovation development? (Large companies, SMEs, consultants, public bodies, e.g. business support, non-profit organisations?) 
- What implications has past collaboration had on your organisational practices regarding innovation? What kinds of results has past innovation collaboration produced? (E.g. a widely adopted product or service, new operational model or a process, e.g. in patient care?)

\section{Innovation development and co-creation in inDemand}

- How is the inDemand model different from your usual way of developing and acquiring innovations?

- What is the value of the model to your organisation in terms of its newness? (E.g. a completely novel way to test and conduct innovation collaboration? Validating the approach at the organisational level?)

\section{Anticipated impact of inDemand}

- What do you see as the biggest challenges for the permanent implementation of the model? (E.g. internal procurement practices, organisational processes, strategy, funding?)

- What do you see as the biggest impact of the inDemand model? What is a good end result? (Please state 1-3 results)

\section{inDemand questionnaire for Solvers}

Innovation co-creation This questionnaire examines how your organisation currently funds its activities and collaborates with the public sector. The questionnaire explores this topic by asking questions which have been thematically categorised under three main approaches described below. Please consider these guidelines when answering the questions.

1 Where are we now? Current practices in how you have, or have sought to collaborate with healthcare organisations and sought to commercialise your solutions

2 What will be different in the future? What are your main expectations for the inDemand model and what are you seeking to achieve? What is the main motivation for your participation in the inDemand project?

3 Impacts and implications How do you anticipate inDemand will develop your current business and create new business for your company?

Background questions (mandatory questions) Name, Organisation, The size of organisation, Role in the organisation, Role in the inDemand co-creation process

How do you mainly seek to develop your business, identify business opportunities and customers?

Who are your main customers in general? Regarding this specific solution? Where are your markets (national, international)?

\section{Have you participated in innovation collaboration and co-creation before?}

- Yes / No. If you answered yes, please state with whom (other SMEs, large corporations, healthcare organisations, other public sector organisations, end users).

- What are the biggest challenges in collaborating with the public sector in your opinion? 
- How has past innovation collaboration with a hospital affected your business practices and business development activities? What are the key opportunities and challenges?

\section{Motivation to participate in the inDemand project}

- What are the planned activities in the co-creation process during the pilot?

- What are your expectations concerning the commitment and participation from healthcare professionals? Who should be involved? (E.g. doctors, nurses, hospital management, IT development etc.)

- What kind of support do you expect to get? What kind of support do you need (included or not)?

\section{What do you expect to have in place after the pilot?}

- What are the expected benefits and value of the co-creation process for your business? Select all that apply. PoC (Proof of Concept), A Hospital as end customer, Access to end customers if patients, Route to international markets, faster entry to market, fundamental technology breakthroughs, new products and features, increased sales and profits, other, please specify.

- How do you anticipate demand-driven innovation collaboration to develop your current business? Why?

\section{inDemand questionnaire for Supporters}

Supporters This questionnaire examines how your organisation provides business support for small and medium sized enterprises. The questions have been thematically categorised under three main approaches described below. Please consider these guidelines when answering the questions.

1 Where are we now? What business support practices, approaches and methods are offered to SMEs by you at the moment?

2 What will be different in the future? How do you expect the inDemand model to change your practices? What new or alternative methods of business support does demand-driven collaboration present to your organisation?

3 Future impact and implications How do you anticipate inDemand to change or add to your practices? What implications and results will inDemand produce concerning business support?

Background questions (mandatory questions) Name, Organisation, The size of organisation, Role in the organisation, Role in the inDemand co-creation process

\section{Where are we now? Current business support practices in your organisation}

- What business support practices, approaches and methods are offered to SMEs by your organisation at the moment?

- What innovation collaboration activities do you participate in in your local ecosystem? How do you engage SMEs in innovation collaboration? 
- Have you collaborated with public healthcare organisations and hospitals before? Yes/No. If you answered yes, how? What were the main challenges you have identified in past healthcare collaboration?

\section{What will be different in the inDemand process?}

- What are the planned business support activities in the inDemand co-creation process (e.g. business model canvases, involvement of investors, etc.)? Please, describe the business modeling activities planned in some detail. Please also explain why this business support approach was selected.

- How do you ensure that your support activities are aligned with the requirements of healthcare organisations?

\section{What will the results of the inDemand project be?}

- Please list 2-3 good results of the inDemand project from your organisation's perspective

- How do you expect demand-driven innovation co-creation to feed into innovation projects beyond inDemand (e.g. applicability to other sectors)?

\section{inDemand questionnaire for Funders}

Innovation calls This questionnaire asks respondents to describe how their organisation funds innovation calls and SME activities in public innovation projects. The questions in the questionnaire have been thematically categorised under three main approaches described below. Please consider these guidelines when answering the questions.

1 Where are we now? How does your funding organisation currently organise, publish and operate innovation calls?

2 What will be different in the future? What expectations do you hold for the inDemand model? How do you think that demand-driven needs identification will impact the organisation of innovation calls?

3 Impacts and implications What permanent implications and results do you expect inDemand to produce for funder organisations as a result?

Background questions (mandatory questions) Name, Organisation, The size of organisation, Role in the organisation, Role in the InDemand co-creation process

\section{Current innovation funding practices}

- Have you funded demand-driven calls for innovation co-creation before? Yes/No. If you answered yes, what level (select all that apply) of funding did you provide? Regional, International.

- If you have funded (demand-driven) calls for innovation co-creation before, what were the main challenges identified, and why?

\section{How does the inDemand model change the innovation call?}

- What expectations do you have for inDemand? How is the inDemand model different from your existing practices? 
- What are the planned selection criteria for the current inDemand innovation call? What kinds of rules and requirements have been set for the applying companies? How are they selected? What are the terms of payment and reimbursement?

\section{What is the expected impact of inDemand?}

- What implications does the inDemand model have on the funding of innovation co-creation? (E.g. what financial mechanisms are applicable to the Challenger organisation after the successful pilots?)

- How exportable is the inDemand model intended to be to other regions?

In the middle of project: Co-creation surveys to Challengers, Solvers, Supporters, Funders

\section{inDemand questionnaire for Challengers}

Innovation co-creation Please describe your experiences so far about the co-creation process.

Background questions (mandatory questions) Name, Organisation, Job title.

- In your opinion, how have the activities carried out so far as part of the InDemand project impacted the solution development? Scale: useless 1-7 very useful.

- What kind of added value has so far been produced by the project?

- How useful was the meeting with the companies at the Kickoff / the opening session? Scale: useless 1-7 very useful.

- Which indicators and procedures are used to assess the impact of the solution development (own estimate) (e.g. patient-orientation, operational efficiency and cost-effectiveness, flexible use of shared resources, operational impact)?

- Is the process being carried out as part of the inDemand project suitable as part of the hospital's innovation activities? Yes/No. Give reasons for your answer

\section{inDemand questionnaire for Solvers}

Innovation co-creation Please describe your experiences so far about the co-creation.

Background questions (mandatory questions) Name, Organisation, Job title.

- How useful was the discussion with the specialists at the Kickoff / the opening session? Scale: useless $1-7$ very useful.

- In the discussions with specialists, what new information did the Kick-Off event bring regarding the real requirements for the solution proposal?

- How has the information obtained from the Kickoff influenced solution planning or development? Scale: useless 1-7 very useful.

- What business model component have you been working on since the Kick-Off? 1 Problem/challenge 2 Customer segments 3 Unique value proposition 4 Solution 5 Channels 6 Revenue streams 7 Cost structure 8 Key metrics 9 Unfair advantage. 
- Please identify the changes.

- We haven't worked on the business model. Why not?

- How much potential for your business activities do you see in the application being developed? Scale: useless 1-7 very useful.

- How useful has it been for your business to work on the business model? Scale: useless 1-7 very useful.

- Has your business approved a solution proposal with other potential customers as well? Yes/No. If yes, how many / where / domestic, or international?

- Up to now, how helpful have you found the joint development of the InDemand project?

- For a public testimonial, what is the added actual value you have got from inDemand? Pluses / Minuses

- Development proposals

- Voluntary feedback to the responsible hospital staff / project workers

\section{inDemand questionnaire for Supporters and Funders}

Innovation co-creation Please describe your experiences so far about the co-creation.

Background questions (mandatory questions) Name, Organisation, Job title.

- How helpful did you find the discussions with different groups during the joint development session? Scale: useless 1-7 very useful.

- Describe in your own words how information moves between different actors? Pluses / Minuses

- Development proposals

- For a public testimonial, what is the actual added value you got from inDemand?

- Voluntary feedback to the responsible hospital staff / project workers

End of Project: Interview Questions for the Solvers and Challengers

End of Project Interview Questions for the Solvers

\section{Where Are We Now?}

- Did your company achieve the expectations you had in the beginning of the project (Expectations Survey*)?

- Have your company's current practices in the innovation activities (R\&D and new business development) changed during the inDemand project? If yes, how?

\section{The New Co-Created Solution - Success and Impact}

- Are you satisfied with the new co-created solution?

- What kind of impact(s) your company will get from the solution? (e.g. cash flow, references, new customers, etc.) 
- How inDemand project has developed your business so far?

- Will the inDemand process speed up to get your product to the market?

- What kind of competitive advantage inDemand project creates for your company? (What kind of strength and advantage do you have in comparison to your competitors after participating in this project?)

\section{inDemand Model and Role of Regional Partners in the inDemand Project}

- Kindly describe each stakeholder role and tasks in the inDemand project in your point of view:

Challenger - Healthcare Organisation. Funder - Regional Funding Organization. Supporter Regional Business Development Agency/Intermediate Organisation.

- What kind of knowledge each of the Regional Partners' personnel should have? What kind of support did you get from each Regional Partner?

- Would you have needed some other type of support? What? How would you improve the support actions?

\section{Call for Solvers - Challenge Description}

- In your point of view, how the Challenges were described in the Call for Solvers at the inDemand Web Site? *E.g. clarity, consistency, quantity of information, etc.

- Did you participate in the regional inDemand challenge information meeting during the Call for Solvers? If yes; how useful that event was?

\section{Co-creation - The Implementation}

- In your opinion, what are the most important aspects in the co-creation development process?

- How did you co-operate with different health care professionals during the co-creation period? (e.g. face-to-face/online meetings, emails, Slack, etc.)

- Did you have co-operation with other inDemand Solver Companies and their Challenges and Intrapreneur Teams? If, yes, please describe.

- How useful you found the group workshops vs. one on one meetings with health care professionals?

\section{Knowledge Management}

- How was knowledge managed in the co-creation process?

- What kind of new knowledge you have gained and learned during the inDemand project?

- What were the biggest challenges in the knowledge sharing?

- How this new knowledge will help you in the future in collaboration with different partners of the inDemand model?

\section{Business Support Implementation}


- inDemand model included tailor made business support with regards to business modelling, access to funding and access to market. What impact does business support have in your opinion in the co-creation process?

- Project deliverables included Lean Canvas and Go to market plan. How did you find working with these documents/tools?

- How did you find importance of these documents as part of the commercialization of the new solution?

- How did you develop the business model during the inDemand project?

- What is your current revenue model?

- Did you change the revenue model during the inDemand project?

- How are you planning to get the revenue with the inDemand solution? Are you going to fit it into your current revenue model or are you going to plan something new?

- Who are you going to sell the solution to and how?

- Have you validated the inDemand solution with other potential customers?

- How did you use the hospital personnel feedback to create a value proposition for them?

- How was the value proposition received by the hospital personnel?

- What were the challenges, if any, in communication?

- Did your previous experiences with hospitals help you in this co-creation process?

\section{Open Innovation - Description and Atmosphere}

- How do you describe open innovation?

- Is the open innovation as innovation process model important to your company?

- Is open innovation in your overall company strategy?

- How do you describe the atmosphere in the open innovation process in the inDemand?

- Was it reliable (trustworthy)?

- Was everybody motivated to innovate openly?

\section{Open Innovation - Best Practices}

- How did your previous innovation processes differ from the inDemand model?

- Why is inDemand better/worse than previous ones? (e.g. technology push approach)

- What is motivating you to work together with other inDemand types of open innovation projects in the future?

\section{Sustainability}

- Please, describe your business opportunity. Has it changed during the co-creation process?

- How? Please, describe its natural, social or economic impact beyond the company boundaries. 
- Please, describe your value proposition. Do you think that a new solution helps to create value for the whole range of stakeholders and the natural environment, beyond customers and shareholders? If yes, please, describe.

- Has your competitive advantage changed during the process? Can you outperform your rivals and maintain natural, social, and economic capital beyond organizational boundaries?

\section{End of Project Interview Questions for the Challengers}

\section{Where Are We Now?}

- Did you achieve your expectations? (Why/Why not)

- Have your organization's current practices in the innovation activities changed during the inDemand project? If yes, how?

\section{inDemand Model and Role of Regional Partners in the inDemand Project}

- Did you achieve your expectations? (Why/why not)

- Have your organization's current practices in the innovation activities changed during inDemand project? If yes, how?

- Kindly describe each stakeholder role in the inDemand project: Challenger representative persons - Healthcare Organisation. Solver - Selected Company. Funder - Regional Funding Organization. Supporter - Regional Business Development Agency/Intermediate Organisation.

\section{Challenge Definition}

- What happened in the challenge definition?

- How did the idea become a challenge?

- What kind of criterions come out for the future?

- What would you describe as best practices to be used in the future in the challenge identification? (Why?)

\section{The New Digital Health solution - Success and impact}

- What is your estimation; what are clinical/functional improvements to the hospital process due to the solution?

- Is there any risk included to the solution?

- How did the expectations come true in the solution?

- Are you satisfied with the solution co-created, how do you estimate?

- Are the medical and nurse teams satisfied with the product?

- What is the solution's impact on the patients?

- What is the solution's impact to the hospital staff or unit efficiency?

- How is the technical feasibility of the solution achieved? What is the usability level of the developed solution? 
- Is there an intention to buy or use the solution? (Why, why not?)

\section{Co-creation}

- What was working well? (Why?)

- What was difficult (Why?)

- How did you co-operate with companies during the co-creation period (e.g. face-to-face/ online meetings, emails, Slack, etc.)?

- What kind co-operation you have with other healthcare professionals and their Challenges? If yes, please describe.

\section{Co-creation Knowledge Management}

- How the information/ knowledge was shared in the co-creation process?

- How was information / knowledge shared for you to enterprise and from enterprise to you in co-creation?

- Was there any other information /knowledge source?

- How was the information / knowledge managed in the co-creation process? (Who manage the knowledge in the co-creation)

- What was encouraged to knowledge creation and sharing?

- What were the biggest challenges of information/ knowledge sharing?

- How the information/ knowledge was shared in the co-creation process?

- What kind of new information/knowledge you learned in the inDemand project?

- How this new knowledge will help you in the future in collaboration with companies, business support organizations, Regional Funder organizations?

- How you could use the new knowledge after the inDemand project?

\section{Open innovation - Description and Atmosphere}

- How do you describe open innovation?

- How do you estimate the atmosphere of the open innovation process in the inDemand?

- Was it reliable (trustworthy)?

- Was everybody motivated to open innovation? (Why/ why not?)

- Did you receive enough support and from who? If not, what kind of support did you expect to receive?

\section{Open innovation - Differences and Benefits}

- Which have been the benefits of the inDemand process? (Open innovation benefits)

- Which have been the biggest problems in the inDemand process, and why?

\section{Open innovation - Best Practices}


- What practices will you keep after the project, what will you leave out, why?

- What do you think about the innovation together with companies? (Problems \& challenges)

- What is motivating you to work together with companies after the project?

- How this innovation would be exploited in other hospitals?

- How would the solution influence the education needs of the staff?

- What kind of public procurement means you have been pressed with the inDemand project?

- Have your organization's current practices in the innovation activities changed during the inDemand project? If yes, how?

- Are these practices and activities repeated now on a daily basis? 


\section{Biographies}

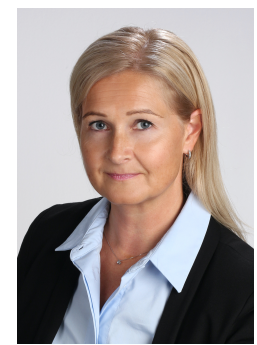

Heini Malm. Heini Malm works as Senior Advisor, Business Development, in BusinessOulu, Economic Development Organisation, City of Oulu. She is currently working as a WP Leader for co-creation and business support implementation in the H2020 Horizon inDemand pilot project. She has coordinated a variety of startup services, industry cluster development (health \& life science, energy sector) and foreign direct investment activities. Prior to her engagement in the public sector, she worked in the wellness (Polar Electro, 2002-2008), telecommunications (Telia Ltd, 2000-2002) and hospitality industries (Marriott International UK \& the U.S., 1996-1998) in business development positions. She holds a graduate diploma from the Global Leader Program, Aalto University Executive Education, Helsinki, Finland; M.Sc. (Economics), University of Oulu, Finland; and BA (Hons) International Hotel Management, University of Cardiff, UK. In addition to open innovation management, Heini's previous research interests included new business opportunity recognition in wellness and health and customer loyalty systems in the hospitality industry.

CRediT Statement: Missing, please complete

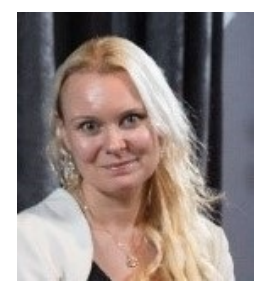

Minna Pikkarainen. Minna Pikkarainen is a joint Connected Health professor at the VTT Technical Research Centre of Finland and at the University of Oulu in the Oulu Business School, Martti Ahtisaari Institute and Faculty of Medicine. As a professor of connected health, Minna is doing multidisciplinary research on innovation management, service networks and business models in the context of connected health service co-creation. Professor Pikkarainen has an extensive record of external funding, and her research has been published in a large number of journal and conference papers, e.g. in the field of innovation management, software engineering and information systems. During 2006-2012, Professor Minna Pikkarainen has been working as a researcher in Lero, the Irish software engineering research centre, as a researcher in Sirris, the collective ?centre of the Belgian technological industry' and as business developer at Institute Mines Telecom in Paris, and at the EIT (European Innovation Technology) network in Paris and Helsinki. Her key focus areas as a business developer have been in healthcare organizations. Previously, Minna's research has been focused on the areas of agile development, software innovation and variability management.

CRediT Statement: Missing, please complete

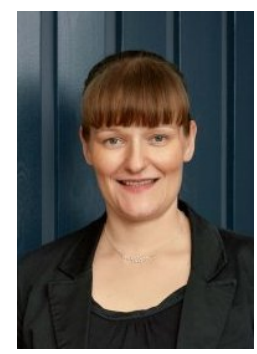

Elina Hyrkäs. Elina Hyrkäs works as a Postdoctoral researcher at the University of Oulu Oulu Business School. She has worked as a Research Director at the Oulu Southern Institute, University of Oulu, Finland. She has done scientific research work for over 15 years, both on the national and international levels. Previously, among other things, she has directed a wide cooperation project; the focus of the project was to develop wellness as a field of research in the region of Oulu South. Her research interests include knowledge management in general and especially strategic-based competence management, innovation management, open innovation and co-creation.

CRediT Statement: Missing, please complete

\section{ISSN 2183-0606}

http://www.open-jim.org

http://creativecommons.org/licenses/by/3.0 